\title{
Left Anterior Descending Artery Ostium
}

National Cancer Institute

\section{Source}

National Cancer Institute. Left Anterior Descending Artery Ostium. NCI Thesaurus. Code C116175.

The opening of the left anterior descending coronary artery at its origin. 